\title{
Research on Experimental Teaching System Structure based on Cultivating the Innovation Ability
}

\author{
Han Xichang* \\ Shen Yang Institute of Engineering \\ Automatic Control Department \\ Shenyang, China \\ Hanxc@sie.edu.cn \\ * Corresponding Author \\ Zhu Xiaojuan \\ Shen Yang Institute of Engineering \\ Automatic Control Department \\ Shenyang, China \\ zhujx@sie.edu.cn
}

\author{
Zhang Yuyan \\ Shen Yang Institute of Engineering \\ Automatic Control Department \\ Shenyang, China \\ zhangna@sie.edu.cn
}

\author{
Liang jie \\ Shen Yang Institute of Engineering \\ Automatic Control Department ZB121 \\ Shenyang, China \\ liangjie@ $\underline{\text { sie.edu.cn }}$
}

\begin{abstract}
Experimental teaching is an important and indispensable link in the process of cultivating creative talents. It is very important to explore practical teaching system in cultivating applied talents for Local Universities. In this article, the existing problems of the automation practice teaching is discussed. The experimental teaching system based on two principles, three-level, four-module is constructed, which includes building experiment teaching system, perfecting the laboratory management, detailing assessment and optimizing teaching effect. The practical effects on cooperation research, laboratory opening and scientific-technological activities of students are described in details. The practice teaching system based on cultivating innovative ability is a complex large system engineering, which includes the innovative ability of students and instructor training of teachers. It has a certain reference value for cultivating automation innovative talents according to personnel training needs of laboratory construction and teaching reform direction.
\end{abstract}

Keywords-Experimental teaching system; Cultivation of talents; Teaching reform; Innovation ability; Automation specialty

\section{INTRODUCTION}

In recent years, the issue of innovative talent training attracts attention from the educational circles to the whole society. Experiment teaching is an important link for engineering universities, especially automation engineering colleges, to cultivate students' innovation consciousness, and improve the practice ability as well as enhancing their own quality. And it is an effective way to optimize the college students' knowledge structure and quality structure. Experimental teaching is an important and indispensable link in the process of cultivating creative personnel, which in the process of training innovation talents, plays a decisive role[1-3].

For the deficiency on the experimental teaching, long-term exploration and attempt at reform has been carried out on the experiment teaching in the school of the author. A distinctive experimental teaching system has been built, rich experience and good results has gained as well [4-6].

\section{EXISTING PROBLEMS ON PRACTICAL TEACHING OF AUTOMATION SPECIALTY}

Summarizing former automation specialty experiment teaching experience, factors which are not conducive to cultivating students' innovative ability are as followed [7$10]$.

- Experiment content is single. The verification experiment has a greater proportion, lacking innovative experimental project. A lot of professional basic course experimental teaching content is often designed according to the theory of curriculum knowledge. Since the experiment content is not related with engineering application, students will lose learning enthusiasm and initiative. Take principle of automatic control course as an example, many schools adopt experiment boxes with one single standard control principle, and the experiment box replaces engineering object with stimulating electronic system, so that the students will find it difficult to have the conception of real engineering. From the perspective of the arrangement of experimental contents, experimental content is given priority to verification. For example, the dynamic characteristics observations on first order and second order system, whose experimental content is same as the traditional teaching. Although it does help to the understanding of textbook knowledge, there are still differences with engineering application.

- Since there is no enough space for experiment and the limitation of experimental equipment, the content suitable for students' teamwork lacks. No 
enough experiment room results in limitation of the number of experiment equipment. Some experiments need more students, working as a group, to communicate and coordinate with each other to complete. But the experiment course arrangement ignores this practical problem. With the basic theory and validation in the majority, there is not much suitable content for teamwork, which often leads to a student's good performance, while the other in the group is copying the conclusion to cope.

- Laboratory management system is not appropriate. There exists too many laboratory management leadership, resulting in a leaderless situation. For example, experimental teaching activities are under the management of student service center, and laboratory construction is under the management of lab and equipment management center while the personnel department deals with experiment teachers' training. Since there is no unified management and laboratories scattered in different institutes, there will be problems such as redundant construction. Team of laboratory construction and management is not scientific and team personnel structure is inappropriate, there is not a perfect evaluation method and incentive mechanism, making the team not stable and it is hard to make a breakthrough to improve experiment teaching quality, which causes a certain restriction to the cultivation of innovative talents.

- Evaluation form is single, lacking strict requirements for the effects on ability training. In the experiment teaching of the past, the experiment result is usually composed of attendance, class performance and experiment report three parts according to certain percentage composition. Because of the large number of the students, class performance scores are often given, to a large extent, depending on the order of the students' completing the tasks, which fairly reflects students' actual operation ability and innovation consciousness. On the aspect of experiment reports, experimental purpose and principle as well as operation are usually in the guide book and the experimental results can be transcribed. Some students work carefully and love to study in depth. Instead of getting good grades, they suffer on grades, so they gradually lost enthusiasm; most students play the role of the passive to watch. Therefore, the experimental teaching doesn't do much good to the effect on students' practical ability, especially the innovation ability and self-study ability.

\section{CONSTRUCTION OF THE EXPERIMENT TEACHING SYSTEM}

Take strengthening students' innovative practice ability as the goal; integrate optimization of fusion experimental resources; create a new experimental teaching mode of "teaching and scientific research closely combined" and "talents cultivated by enterprise and schools"; explore laboratory construction and teaching reform direction that meets the need of talents cultivation in new period to raise students' innovation practice ability. According to the study level and the objective difference between the students, experiment project is divided into various levels. For different students, relate to different experimental teaching program on different hierarchies such as basic skill training, design ability training, comprehensive ability training, and scientific research ability training. Experimental types varied. Setting programs such as stimulation experiments, hardware experiment, curriculum design and comprehensive training. Students and teachers work together to develop experimental equipment to effectively combine theory with practice. Experimental content integrated. Carry out independent course of comprehensive and design type experiment to systematize what they learn.

\section{A. Building "two principles, three levels and four modules" experiment teaching system}

Take strengthening students' innovative practice ability as the goal to build a new experimental teaching system. Insisting on the basic experimental teaching principle of "aiming at ability training and serving students". Design experiment program on three levels, which are basic operational experiment, comprehensive design experiment and the research of innovative experiments. According to the social demand for automation, combining with the characteristics of disciplines, mix all the experimental teaching content into four modules that are detection technology experiment module, control technology experiment module, computer technology experiment module and electrical technology experiment module. Experimental teaching system is shown in Fig. 1.

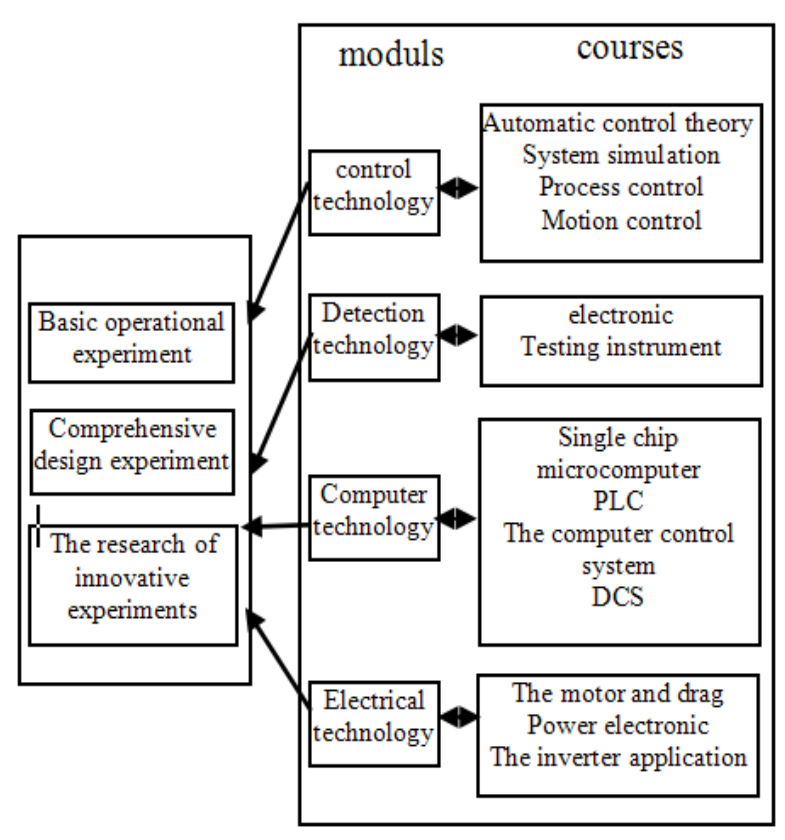

Figure 1 Experimental teaching system

Basic operational experiment is mainly to help students master the basic experimental skills and methods. Key 
points lie in the use of instruments; cultivate students' scientific spirit and the rigorous work style. Basic operational experiment depends much on courses. Experiment mainly aims at helping students get familiar with component that automation controller design involves, such as energy transformation, executing and electromechanical energy conversion or equipment design, use, measuring, debugging and troubleshooting methods, to lay a solid foundation for subsequent professional comprehensive experiment.

Comprehensive design experiment contains a complex system. It needs ability integrated by basic experiments and professional knowledge to finish a task smoothly and successfully. And these experiments will lay a solid foundation for students to carry out their graduation designs.

Experiment module encloses four core technologies of automation applications: detection technology, control technology, computer technology, and electrical applications technology. Use these four technologies as cores to carry out experimental program of related courses.

\section{B. Perfect the laboratory management}

Establish wholesome and perfect rules and regulations of the experimental teaching. Raise the enthusiasm of the experimental teaching management staff by making reasonable rewarding policies. Establish the experimental teaching management regime with the principle of people oriented; strengthen and perfect the construction of experimental teaching management regime according to the needs of experimental teaching management and reform; implement policies such as formulating the experiment teachers and teaching experiment technicians working rules; adjust the ways of employment and evaluation of teaching experiment staff; set up the experimental teachers' work evaluation system, etc. Establish and perfect experiment teaching quality guarantee system; set up the experimental teaching quality guarantee and monitoring system; strengthen the construction of the standardization and experimental courses; distinguish quality standard of every link in experiment teaching. With efforts on target management, process management and quality management in teaching process, ensure the quality of experiment teaching.

\section{Detailed assessment and Optimized teaching effect}

The experiment rating system is perfected. The previous attendance, classroom performance, lab reports usually are classified as grade item. The Grading standard is shown in Table 1. In addition, the experimental operation and written exam are increased. Usually results are $60 \%$ of the total score, the experimental operation and written exam score both are $20 \%$ of the total marks respectively. Experimental score is the weighted average of the results of each experiment. Usually score depends on the course of the learning process. It focuses on learning attitude, classroom discipline and knowledge of student. Experiment operation examination can test students' practical operation level and ability. The written examination is able to urge the students to combine the experimental content and the theoretical knowledge of the classroom. This can enable students to give full play to their own advantages, enhance students' learning initiative.

TABLE I GRADING STANDARD TABLE

\begin{tabular}{|c|c|}
\hline items & Contents \\
\hline \multirow{4}{*}{$\begin{array}{c}\text { Usual } \\
\text { grades } \\
60 \%\end{array}$} & Item difficulty 10\% \\
\cline { 2 - 2 } & Classroom attitude 10\% \\
\cline { 2 - 2 } & Classroom discipline 10\% \\
\cline { 2 - 2 } & ReportQuality 20\% \\
\hline \multirow{2}{*}{$\begin{array}{c}\text { Written } \\
\text { exam } \\
20 \%\end{array}$} & Complete time 10\% \\
\hline $\begin{array}{c}\text { Operating } \\
\text { Results } \\
20 \%\end{array}$ & $\begin{array}{c}\text { Pine connection 5\% } \\
\text { Practices 5\% }\end{array}$ \\
\hline $\begin{array}{c}\text { Overall } \\
\text { score }\end{array}$ & Result analysis 5\% \\
\hline & Instrumentation 10\% \\
\hline
\end{tabular}

\section{PRACTICALEFFECT}

In recent years, the automation teaching team of the school of the author is committed to the reform and research of experimental teaching system. A lot of useful attempt are done and achieved a certain effect. In practical teaching reform process, a teaching team advantage is played; clarify the link between automation professional courses and relevant courses experiments setting. The "detection technology", "control technology", "computer technology" and "Electrical Engineering" other experimental modules are constructed. After years of construction, the school teaching reform of automation has made some remarkable achievements.

Researching cooperation are strengthen and experimental environment is improved. Automation professionals met with Daqing Zijin bridge software company and Biejing Yakong the software company and other enterprises to build campus practice base. And build outside practice base in Liaoning Solar Application Limited Co., and Tieling power plants. These has played an important role in cultivating students practical ability and project awareness.

Strengthen laboratory opened. The laboratory is mainly administrated by students to solve teacher shortages and time constraints. This builds a platform and provides the opportunity to further improve the abilities of students.

Scientific and technological activities of students are carried out. Students consolidate the theoretical knowledge learned, theoretical knowledge comprehensive integrated applications by scientific and technological 
activities. It is indispensable for cultivating students' practice ability. For four years, the students participate the innovation and entrepreneurship training in a total of 24 projects, of which there are 3 national projects, 11 provincial ones and 10 university ones. There are 37 students participated competitions win 2 national first prize, 4 second prize, 5 third prize $5 ; 6$ provincial first prize, 8 second prize and 9 third prize.

\section{CONCLUSIONS}

The practice teaching system based on cultivating innovative ability is a complex large system engineering, which includes the innovative ability of students, and instructor training of teachers, the experimental environment and management systems. The good mechanism must be built by colleges and universities in particular, application-oriented colleges, based on respecting innovators law, encouraging innovation and entrepreneurship environment. It provides solid talent guarantee for innovative country.

The school of the author reforms and innovates continuously on cultivating students' innovative ability, and learns other universities experience, in order to cultivate a new generation of innovative applicationoriented talents according to national policy.

\section{ACKNOWLEDGMENT}

This work was supported in part by Liaoning Province Education Science "Twelfth Five Year Plan" project under Grant No.JG14DB292, JG15DB289 and JG15DB301, Course construction project of quality resources sharing in Liaoning Province.

\section{REFERENCES}

[1] BAO Yan, LI Hongru, XU Lin, Exploration and practice of the reform of experimental teaching of Automation Specialty, Education Teaching Forum, 2013.43 p38-39

[2] MA Jie, LIU Xiaohe, FU Xingjian, Exploration of integration teaching mode with combination of theory teaching and practice teaching, Experimental Technology and Management, 2013.30 (11) p172-175

[3] MA Jie Introduction to engineering technology innovation, Tsinghua University press, 2011

[4] LI Zhan-ming;LI Er-chao;LI Wei; To Develop Students' Practice and Innovation Ability Based on Open Experimental Platform,Research and Exploration in Laboratory 2013.32(11),pp299-399

[5] XIE Yong, ZHANG Tianping, FANG Yu, Exploration on establishing the evaluation system of the practical ability of automation specialty , Experimental Technology and Management Vol.28 No.1 Jan.2011p12-15

[6] HE Xiaoxi, ZHONG Weifeng, ZHOU Wei,Exploration and construction of practical teaching system for innovative talents cultivation Heilongjiang Education(Higher Education Research \& Appraisal),2014.1 p75-76

[7] DENG Xiaoyan, CHEN Liding, YUAN Ling, Research on the construction of the diversified innovative practice teaching platform for automation specialty, Information Technology,2013.07,pp37-43

[8] TANG Jiu-yang;HU Sheng-ze;GE Bin;TANG Da-quan;XIAO Wei-dong, Experiment Teaching Reform for Innovation Ability Enhancement, Journal of Higher Education Research, 2014.30 (1) p107-109

[9] LU Yuan, LI Xuyun, YE Guozhi, Study on new teaching mode of enhancing students capacity in independent study, independent experiment and independent innovation , Experimental Technology and Management Vol.29 No.6 Jan.2012p11-16

[10] SUN Li,LIU Yong-chen,CHANG Lü, Building of Applied Innovative Talents Training System in Local Colleges ,Research and Exploration in Laboratory,2011.30(1),pp143-145X Yu, P Shum, G B Ren, N Q NgoPhotonic crystal fibers with high index infiltrations for refractive index sensing $[\mathrm{J}]$, Optics Communications, 2008, 281: 4555-4559. 